\title{
Erratum to: Reoperation rates after laparoscopic fundoplication
}

\author{
Tianzan Zhou - Cristina Harnsberger - Ryan Broderick - Hans Fuchs • \\ Mark Talamini • Garth Jacobsen - Santiago Horgan - David Chang • \\ Bryan Sandler
}

Published online: 10 January 2015

(c) Springer Science+Business Media New York 2015

\section{Erratum to: Surg Endosc \\ DOI 10.1007/s00464-014-3660-1}

There is a shared first authorship between the first two authors, T. Zhou and C. Harnsberger, as both contributed equally to this paper.

The affiliation for $\mathrm{T}$. Zhou should be:

Department of General Surgery, Division of Minimally Invasive Surgery, Center for the Future of Surgery, University of California, San Diego, San Diego, CA, USA
The affiliation for C. Harnsberger, R. Broderick, H. Fuchs, G. Jacobsen, S. Horgan, D. Chang, B. Sandler should be:

Department of General Surgery, Division of Minimally Invasive Surgery, Center for the Future of Surgery, University of California, San Diego, San Diego, CA, USA

The affiliation for M. Talamini should be:

Department of Surgery, Health Sciences Center T19-020, Stony Brook Medicine, Stony Brook, NY 11794-8191, USA

The online version of the original article can be found under doi:10. 1007/s00464-014-3660-1.

T. Zhou · C. Harnsberger $(\bowtie) \cdot$ R. Broderick · H. Fuchs ·

G. Jacobsen $\cdot$ S. Horgan - D. Chang - B. Sandler

Division of Minimally Invasive Surgery, Department of General

Surgery, Center for the Future of Surgery, University of

California, San Diego, San Diego, CA, USA

e-mail: charnsberger@ucsd.edu

M. Talamini

Department of Surgery, Health Sciences Center T19-020, Stony

Brook Medicine, Stony Brook, NY 11794-8191, USA 